\title{
Direct-write assembly of 3D scaffolds using colloidal calcium phosphates inks
}

\author{
Raquel C. Richard ${ }^{1}$; Renata N. Oliveira ${ }^{1}$,
} Gloria D.A. Soares ${ }^{2}$, Rossana M.S.M. Thiré ${ }^{1}$

\author{
${ }^{1}$ Laboratory of Biopolymers - PEMM/COPPE, Federal University of Rio de Janeiro, PO Box: 68505, Rio de Janeiro, \\ RJ, Brazil \\ ${ }^{2}$ Institute of Biomedical Sciences, Federal University of Rio de Janeiro, Rio de Janeiro, Brazil \\ e-mail: raqcs@metalmat.ufrj.br; renataoliveira@poli.ufrj.br; gloria.soares@gmail.com; rossana@metalmat.ufrj.br
}

\begin{abstract}
Additive manufacture techniques using concentrated colloidal inks are a promising approach for creating three-dimensional (3D) calcium phosphates scaffolds for bone repair and regeneration. Among those, the direct-write assembly allows building scaffolds with precise size and geometry. In the present work, commercial $\beta$-TCP and HA were used to produce two types of colloidal ink. According to the ink composition used to build the scaffolds, two different groups were obtained. Group I: scaffolds produced with $\beta$-TCP-based ink; and Group II: scaffolds produced with biphasic CaP-based ink (BCP). The 3D scaffolds were assembled in a cylindrical shape $(\Phi=8 \mathrm{~mm} \times \mathrm{H}=16 \mathrm{~mm})$ with interconnected pore channels of approximately $500 \mu \mathrm{m}$ by robotic deposition of 64 layers using a robocasting machine. The mechanical compression property of the scaffolds was determined using universal testing machine. To assure the controlled geometry of the scaffolds, digital images were obtained by reconstructing each individual scan obtained with a micro-computed tomography. An optical contact angle measurement system was used to evaluate the wettability of the materials. After analyzing the results it was concluded that: the robocasting system is suitable for building 3D periodic calcium phosphates scaffolds; the direct-write assembly didn't change the hydrophilic characteristic of $\mathrm{CaPs}$; and presented mean compressive strength around $11 \mathrm{MPa}(\beta-$ TCP group) and $15 \mathrm{MPa}$ (BCP group), which is compatible with trabecular bone.
\end{abstract}

Keywords: calcium phosphates scaffolds, robocasting, bone engineering.

\section{INTRODUCTION}

During the past years, several techniques had been developed in order to repair extensive bone loss, nevertheless it remains a challenge because each technique has its limitation. Autogenous bone grafts have not just morbidity associated, but restriction in the quality and quantity of bone available for donation to the recipient site. Allografts have a significant incidence of postoperative infection as well as potential for disease transmission [1]. Considering this, using synthetic bone graft materials to control the complications associated with the current techniques seems to be a powerful alternative.

Examples of commercial synthetic calcium phosphate compounds used as bone graft materials include: hydroxyapatite (HA); tricalcium phosphate (TCP); and biphasic calcium phosphate (BCP). The last one consist of a homogeneous mixture of hydroxyapatite $\left(\mathrm{HA}, \mathrm{Ca}_{10}(\mathrm{PO} 4)_{6}(\mathrm{OH})_{2}\right)$ and beta-tricalcium phosphate $\left(\beta-\mathrm{TCP}, \mathrm{Ca}_{3}(\mathrm{PO} 4)_{2}\right)$ in varying $\mathrm{HA} / \beta-\mathrm{TCP}$ ratios $[2]$. One attractive feature of $\mathrm{BCP}$ is that the preferential dissolution of $\beta$-TCP compared to HA allows controlling the bioactivity or biodegradation of the material by varying the HA/ $\beta$-TCP ratio [3].

It's known that filling the bone defect with a porous scaffold helps to enhance bone regeneration since the scaffold serves as a template for cell ingrowth and interactions as well as for extracellular bone matrix formation [5]. Conventional methods for scaffold fabrication such as gas foaming, salt leaching, fiber meshing and emulsification are widespread, but they cannot produce a scaffold with full control of geometrical parameters (e.g. pore size and interconnected porosity) $[5,6]$. It has been shown that 3D porous scaffolds, reproducing the shape of the patient's bone defect, have a great biocompatibility after the surgical procedure $[7, \underline{8]}$.

Additive manufacture techniques as three-dimensional (3D) printing, laser sintering, stereolithography, 
fused-deposition-modeling and direct-write assembly allow the fabrication of customized scaffolds with complex shapes and high reproducibility from a computer-aided design (CAD) model. Among the additive manufacture methods, direct-write assembly is a technique that uses water-based inks, with minimal organic content $(<1 \mathrm{wt} \%)[4, \underline{5}, 6]$. By adjusting the ink composition and viscoelasticity, calcium phosphates scaffolds can be built with minimal organic content and without the need for a sacrificial support material [9]. Furthermore, this technique employs an ink delivery system mounted on a z-axis motion-controlled stage onto a moving $x-y$ stage, which allows building scaffolds with accurate size and geometry.

Given the above considerations, robocasting may be a promising approach for creating three-dimensional (3D) calcium phosphates scaffolds for bone repair and regeneration. Therefore, the aim of this work was to build periodic scaffolds for bone regeneration using robocasting technology associated with $\beta$-TCP and BCPbased colloidal inks.

\section{MATERIALS AND METHODS}

Commercial $\beta$-TCP (Sigma-Aldrich, Germany) and HA (Honeywell, Germany) powders were used to produce two types of colloidal ink containing proper amounts of: double distilled water; dispersant (Darvan ${ }^{\circledR}$ 821A, R.T. Vanderbilt Company, Inc. Norwalk, CT, USA); hydroxypropyl methylcellulose (Methocel F4M, Dow Chemical Company, Midland, MI, USA); and poly(ethyleneimine) (PEI, ICN Biomedical, Aurora, OH, USA). Table 1 displays the approximate amount of reagents employed to produce the colloidal ink, while Fig. 1 reveals the consistence of the $\beta$-TCP colloidal ink.

Table 1: Approximate amount of reagents employed to produce $\beta$-TCP and BCP colloidal inks.

\begin{tabular}{l|c|c}
\hline & $\boldsymbol{\beta}$ - TCP INK & BCP INK \\
\hline$\beta$-TCP powder (g) & 64 & 32 \\
\hline HA powder (g) & - & 32 \\
\hline Double distilled water (g) & 16 & 16 \\
\hline Dispersant (g) & 1 & 1 \\
\hline Hydroxypropyl methylcellulose (g) & 4.8 & 4.8 \\
\hline Poly(ethyleneimine) (g) & 1 & 1 \\
\hline
\end{tabular}

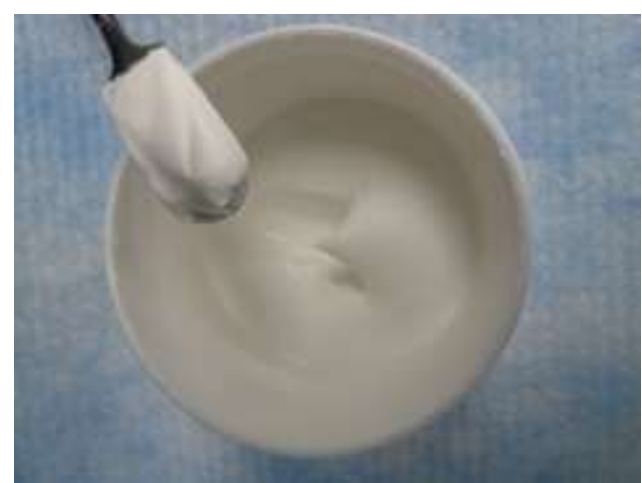

Figure 1: $\beta$-TCP ink consistence. Notice the stiff peak formed once a spatula is pulled straight up out of the ink.

The scaffold design (Fig. 2) was create using the RoboCAD Special Shapes tool (RoboCAD Beta, Stillwater, OK, USA) following these parameters: lattice builder; round lattice; radius 4; z spacing- 0.259 mm; $\mathrm{n}$ layer64 (number of layers); $n$ perimeter- 2 (number of external rings surrounding the lattice pattern); Dx and Dy0.9 (distance between the center of the rods). 


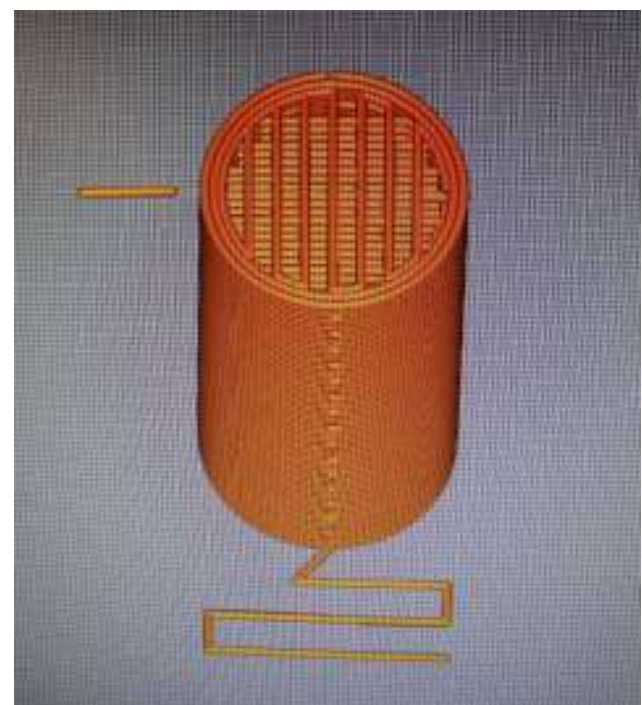

Figure 2: Computer-aided design of the scaffolds.

The ink was placed in a syringe coupled to a direct-write assembly machine, Fig. 3, (Aerotech Inc, OK, USA) and deposited through a cylindrical deposition nozzle (diameter: $330 \mu \mathrm{m}$ ) at a volumetric flow rate and constant $x-y$ table speed $(3 \mathrm{~mm} / \mathrm{s})$. This machine had its 3 -axis motion controlled by a computer-aided directwrite program (RoboCAD 3.0, 3-D Inks, Stillwater, OK, USA), where the scaffold pattern was defined. The 3D scaffolds were assembled in a cylindrical shape with interconnected pore channels. The deposition was performed in non-wetting oil, as shown in Fig. 3, to prevent non-uniform drying during the assembly process. After the assembly, the scaffolds were drained, dried in air for $24 \mathrm{~h}$ and sintered at $1100^{\circ} \mathrm{C}$ for $4 \mathrm{~h}$. Two different groups of scaffolds were obtained, depending on the type of powder used ( $\beta$-TCP or BCP) in the ink preparation. Group I consisted of scaffolds produced with $\beta$-TCP-based ink; and Group II consisted of scaffolds produced with $\beta$-TCP/HA 50/50 (BCP)-based ink.

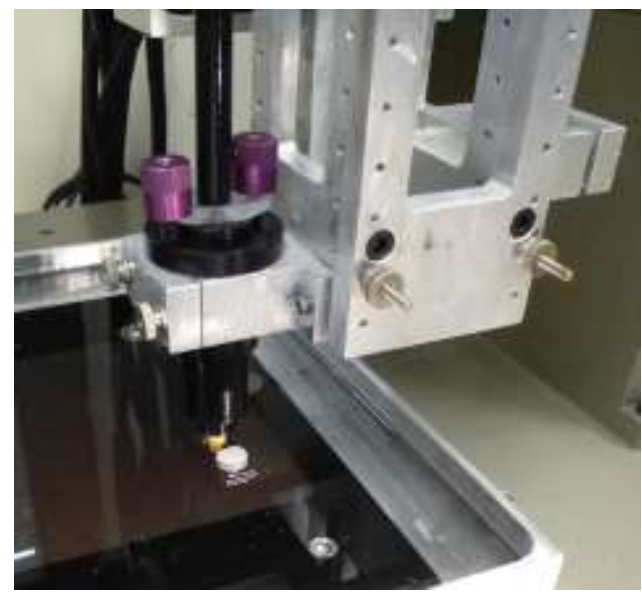

Figure 3: Robocasting machine performing direct-write assembly.

An optical contact angle measurement system (OCA 15, Garden City, NY) was employed to evaluate the

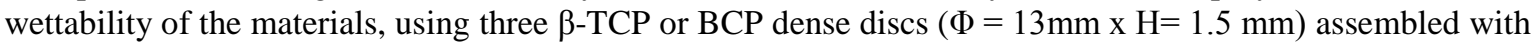
the robocasting machine. The mechanical compression property of the scaffolds was determined using Universal Testing Machine (INSTRON series 5566, Norwood, MA); 15 specimens were tested in each group. To assure the controlled geometry of the scaffolds, digital images were acquired by reconstructing each individual scan obtained with a micro-computed tomography - micro-CT (Scanco Medical, Switzerland). 


\section{RESULTS}

3D structures obtained from the $\beta$-TCP and BCP inks were cylinders $(\Phi=8 \mathrm{~mm} \times \mathrm{H}=16 \mathrm{~mm})$ composed of 64 layers, with two perimeter rims surrounding a parallel array of rods $(0.33 \mathrm{~mm})$ with an inter-rod spacing of, approximately, $460 \mu \mathrm{m}$. Figure 4 reveals the macrostructure of a sintered $\beta$-TCP scaffold. During the layer-by-layer robotic deposition, the layers were rotated $90^{\circ}$ with respect to each other to give raise to an interconnected macroporous network. Interconnected pores can be observed on the micro-CT image, displayed at Fig. 5, obtained from a BCP sintered scaffold.

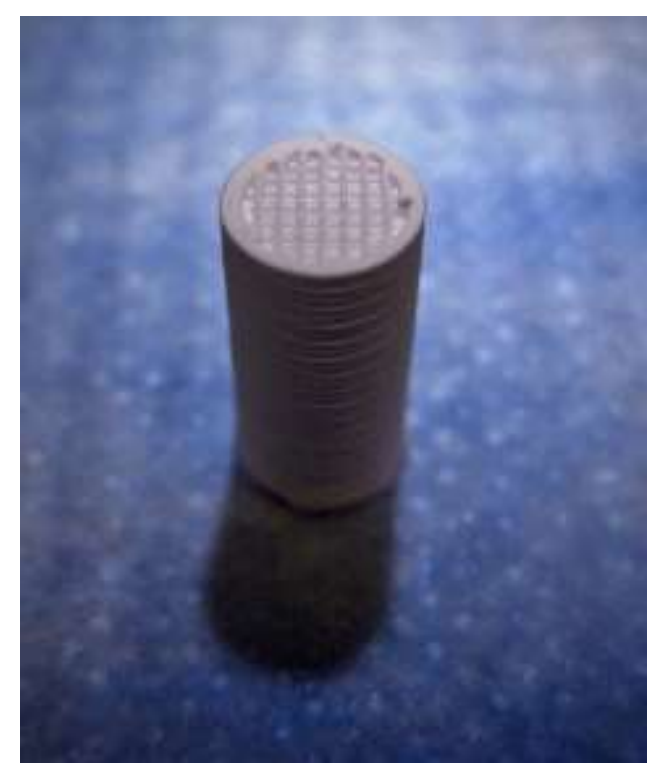

Figure 4: Macrostructure of a $\beta$-TCP scaffold.

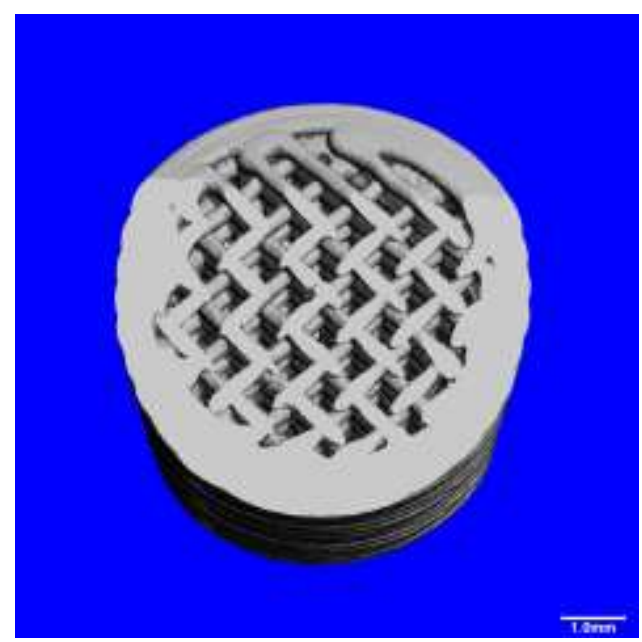

Figure 5: Interconnected structure of BCP sintered scaffold revealed by micro-CT image.

The surface free energy (SFE) analysis assessed the polar and the disperse components of the material. The polar and the disperse components were $39.12( \pm 0.9) \mathrm{mN} / \mathrm{m}$ and $26.18( \pm 0.25) \mathrm{mN} / \mathrm{m}$ for the $\beta$-TCP group; for the BCP group the results were $39.13( \pm 0.08) \mathrm{mN} / \mathrm{m}$ and $28.14( \pm 0.17) \mathrm{mN} / \mathrm{m}$, respectively.

The mechanical analysis revealed the compressive strength values of $\beta$-TCP and BCP scaffolds. Based on the results of the 15 samples analyzed for each test, the average value of the compressive strength was calculated. Those, as well as the maximum value of the compressive strength obtained, are displayed on table 2. The ANOVA analysis on the maximum compressive strength of the samples with different compositions (1-way ANOVA analysis, confidence level of 95\%, not shown) revealed that there was no significative difference between the compressive strength of the samples with different compositions. 
Table 2: Mean and maximum compressive strength values of $\beta$-TCP and BCP scaffolds.

\begin{tabular}{l|l|l}
\hline & $\boldsymbol{\beta}$ - TCP & BCP \\
\hline $\begin{array}{l}\text { Average compressive } \\
\text { strength (MPa) }\end{array}$ & $11( \pm 5.4)$ & $15( \pm 6.9)$ \\
\hline $\begin{array}{l}\text { Maximum compressive } \\
\text { strength (MPa) }\end{array}$ & 26 & 36 \\
\hline
\end{tabular}

\section{DISCUSSION}

The scaffolds assembled by robocasting were designed in order to reproduce in their architecture the typical thicknesses of the bone trabeculae, which are in the range of 100 to $300 \mu \mathrm{m}$, and typical intertrabecular spacing, which is in the order of 500 to $1500 \mu \mathrm{m}$ [10]. Many studies have stated that an optimal scaffold for bone replacement should have a 3D geometry similar of that of the ingrowing trabecular bone, because it may be an effective approach for fast and efficient conduction of new bone across significant distances in these osteoconductive structures $[11,12,13]$.The importance of the pore size and architecture for a scaffold relies on the fact that they are essential for controlling metabolic aspects such as the diffusion of oxygen, growth factors, and nutrients to the cells [14].

The performance of a $3 \mathrm{D}$ bone scaffold is not only related to the biomaterial selection, but also to its architecture and consequent interaction with the surrounding tissue. In order to be considered properly designed, a scaffold should allow bone ingrowth and provide vascularization for the new tissue. This can be achieved by controlling the scaffold pore volume fraction, pore interconnections, and pore size. It's known that a highly interconnected porosity volume fraction provides a large surface area, which facilitates cells to migrate, proliferate, and differentiate $[15,16]$. Both $\beta$-TCP and BCP scaffolds with structured porosity and controlled chemistry have been successfully fabricated by additive manufacture methods using concentrated colloidal inks [17]. In this study, scaffolds with interconnected macroporous were successfully obtained by direct-write assembly, which was confirmed by the micro-CT images. SCHELLER et al. [1] acknowledge that it is difficult to assimilate high porosity and mechanical integrity into a single material design, as mechanical properties are frequently maximized by minimizing porosity. Nonetheless, the mean compressive strength values of $\beta$-TCP (11 MPa) and BCP (15MPa) scaffolds obtained in this study were compatible or higher than that of human trabecular bone. DETSCH et al. [18] disclosed that the bone substitute strength should be between 0.5 and $15 \mathrm{MPa}$, considering a cancellous bone replacement. Studies with trabecular bone have been registered a wide variation of strength which is usually in the range of 4 to $12 \mathrm{MPa}[17, \underline{19}, 20]$.

In the present work, the mechanical properties of $\beta$-TCP and BCP scaffolds (containing 50\% of HA) were statistically similar. Nonetheless, the use of BCP with different HA to $\beta$-TCP ratios allows not only the manipulation of the scaffold's degradation rate but their bioactivity properties [19]. Moreover, it has been shown that BCP improves the formation of new bone inside the implanted scaffold [17]. Calcium phosphatebased bioceramics are widely used in bone repair due to their similarity in composition to the bone mineral [5].

Parameters as porosity and mechanical strength are considered key factors in determining scaffold performance [13]. Another important feature is the surface free energy, which influences cellular adhesion strength and proliferation. It has been shown that low cell adhesion strength is related to the dispersive component of SFE [21]. Previous works also demonstrated that: the more hydrophilic the material the more cells will adhere on the surface $[22,23]$. In this study both groups of scaffolds ( $\beta$-TCP and BCP) presented a larger polar component compared to the apolar one. Additionally, considering that the colloidal ink production as well as the robotic deposition didn't change the hydrophilic characteristic of CaPs, it may represent a relevant characteristic of this technique.

\section{CONCLUSIONS}

Based on the results obtained, it was concluded that: direct-write assembly system is suitable for building 3D calcium phosphates scaffolds for bone regeneration, since scaffolds with periodic morphology and interconnected pores were obtained; both ink composition used in the direct-write assembly resulted in hydrophilic scaffolds with satisfactory mechanical properties for trabecular bone replacement. 


\section{ACKNOWLEDGMENTS}

The authors acknowledge the financial support given by CNPq, CAPES, FAPERJ.

\section{BIBLIOGRAPHY}

[1] SCHELLER, E.L., KREBSBACH, P.H., KOHN, D.H., "Tissue engineering: state of the art in oral rehabilitation", Journal of Oral Rehabilitation, v. 36, pp. 368-389, 2009.

[2] LEGEROS, R.Z., LIN, S., ROHANIZADEH, R., MIJARES, D., LEGEROS, J.P., "Biphasic calcium phosphate bioceramics: preparation, properties and applications", Journal of material science: materials in medicine, v.1, pp. 201-209, 2003.

[3] GARRIDO, C.A., LOBO, S.E., TURÍBIO, F.M., LEGEROS, R.Z., "Biphasic Calcium Phosphate Bioceramics for Orthopaedic Reconstructions: Clinical Outcomes", International Journal of Biomaterials, v. 2011, pp. 1-9, 2011.

[4] American Society for Testing and Materials. ASTM: F2792 - 12a: Standard Terminology for Additive Manufacturing Technologies. USA, 2012.

[5] BUTSCHER, A., BOHNER, M., HOFMANN, S., GAUCKLER, L., MÜLlER, R., "Structural and material approaches to bone tissue engineering in powder-based three-dimensional printing", Acta Biomaterialia, v. 7, pp. 907-920, 2011.

[6] MIRANDA, P., PAJARES, A., SAIZ, E., TOMSIA, A.P., GUIBERTEAU, F., "Fracture modes under uniaxial compression in hydroxyapatite scaffolds fabricated by robocasting", Journal of Biomedical Materials Research Part A, v. 87A, n. 3, pp. 646-655, 2007.

[7] UCHIDA, T., IKEDA, S., OURA, H., TADA, M., NAKANO, T., FUKUDA, T., MATSUDA, T., NEGORO, M., ARAI, F., "Development of biodegradable scaffolds based on patient-specific arterial configuration", J. Biotechnol, v. 133, pp. 213-218, 2008.

[8] LI, J., ZHANG, L., LV, S., LI, S., WANG, N., ZHANG, Z., "Fabrication of individual scaffolds based on a patient-specific alveolar bone defect model”. Journal of Biotechnology, v. 151, pp. 87-93, 2011.

[9] MICHNA, S., WU, W., LEWIS, J.A., "Concentrated hydroxyapatite inks for direct-write assembly of 3-D periodic scaffolds", Biomaterials, v.26, pp. 5632-5639, 2005.

[10] KEAVENY, T.M., MORGAN, E.F., YEH, O.C., Standard Handbook of biomedical engineering and design, New York: The McGraw-Hill Companies; 2004.

[11] MATHIEU, L.M, MUELler, T.L., BOURBAN, P.E., PIOLETTI, D.P., MÜLlER, R., MÅNSON, J.A.E., "Architecture and properties of anisotropic polymer composite scaffolds for bone tissue engineering", Biomaterials, v. 27, n. 6, pp. 905-916, Feb. 2006.

[12] SIMON, J.L., MICHNA, S., LEWIS, J.A., REKOW, E. D., THOMPSON, V.P., SMAY, J.E., YAMPOLSKY, A., PARSONS, J.R., RICCI, J.L., "In vivo bone response to 3D periodic hydroxyapatite scaffolds assembled by direct ink writing”, J Biomed Mater Res A., v. 83, n. 3, pp. 747-758, Dec.2007

[13] SIMON, J.L., REKOW, E. D., THOMPSON, V.P., BEAM, H., RICCI, J.L., PARSONS, J.R., "MicroCT analysis of hydroxyapatite bone repair scaffolds created via three-dimensional printing for evaluating the effects of scaffold architecture on bone ingrowth", J Biomed Mater Res A., v.85, n. 2, pp. 371-377, May 2008.

[14] SIMON, J.L., ROY, T.D., PARSONS, J.R., REKOW, E.D., THOMPSON, V.P., KEMNITZER, J., RICCI, J.L., "Engineered cellular response to scaffold architecture in a rabbit trephine defect", J Biomed Mater Res A., v. 66, n. 2, pp. 275-82, Aug. 2003.

[15] ROY, T.D., SIMON, J.L., RICCI, J.L., REKOW, E.D., THOMPSON, V.P., "Performance of hydroxyapatite bone repair scaffolds created via three-dimensional fabrication techniques", J Biomed Mater Res A., v. 67, n. 4, pp. 1228-1237, Dec.2003.

[16] TAMPIERI, A., CELOTTI, G., SPRIO, S., DElCOGliANO, A., FRANZESE, S., "Porosity-graded hydroxyapatite ceramics to replace natural bone", Biomaterials, v. 22, n.11, pp. 1365-1370, Jun. 2001.

[17] HOUMARD, M., FU, Q., GENET, M., SAIZ, E., TOMSIA, A.P., "On the structural, mechanical, and biodegradation properties of HA/ $\beta$-TCP robocast scaffolds", J Biomed Mater Res Part B. v. 101, n. 7, pp. 1233-1242, Oct. 2013.

[18] DETSCH, R., SCHAEFER, S., DEISINGER, U., ZIEGLER, G., SEITZ, H., LEUKERS, B., "In vitroosteoclastic activity studies on surfaces of 3D printed calcium phosphate scaffolds". Journal of Biomaterials 
appplications, v. 26, n. 3, pp. 359-380, Sep. 2011.

[19] JOHNSON, A. J. W., HERSCHLER, B. A., "A review of the mechanical behavior of CaP and $\mathrm{CaP} /$ polymer composites for applications in bone replacement and repair", Acta Biomaterialia, v. 7, n. 1, pp. 16-30, Jan. 2011.

[20] HUTMACHER, D.W., SCHANTZ, J.T., LAM, C.X.F., TAN, K.C., LIM, T.C., "State of the art and future directions of scaffold-based bone engineering from a biomaterials perspective", J Tissue Eng Regen Med, v.1, n. 4, pp. 245-60, Jul.-Aug. 2007.

[21] SANTIAGO, A.S., SANTOS, E.A., SADER, M.S., SANTIAGO, M.F., SOARES, G.A., "Response of osteoblastic cells to titanium submitted to three different surface treatments", Braz Oral Res, v. 19, n.3, pp.203-208, 2005.

[22] GODDARD, J. M., \& HOTCHKISS, J. H., "Polymer surface modification for the attachment of bioactive compounds", Progress in Polymer Science, v. 32, pp. 698-725, 2007.

[23] Xu, L. C. "Effect of surface wettability and contact time on protein adhesion to biomaterail surfaces", Biomaterials, v. 28, pp. 3273-3283, 2007. 